\title{
Toufic El-Khoury, Beyrouth pantomime
}

\section{Veronica Amadessi}

\section{(2) OpenEdition}

\section{Journals}

\section{Edizione digitale}

URL: http://journals.openedition.org/studifrancesi/6479

DOI: 10.4000/studifrancesi.6479

ISSN: 2427-5856

\section{Editore}

Rosenberg \& Sellier

\section{Edizione cartacea}

Data di pubblicazione: 1 novembre 2010

Paginazione: 605

ISSN: 0039-2944

\section{Notizia bibliografica digitale}

Veronica Amadessi, «Toufic El-Khoury, Beyrouth pantomime», Studi Francesi [Online], 162 (LIV | III) |

2010, online dal 30 novembre 2015, consultato il 09 janvier 2021. URL: http://

journals.openedition.org/studifrancesi/6479 ; DOI: https://doi.org/10.4000/studifrancesi.6479

Questo documento è stato generato automaticamente il 9 janvier 2021.

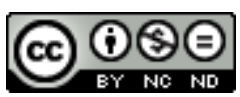

Studi Francesi è distribuita con Licenza Creative Commons Attribuzione - Non commerciale - Non opere derivate 4.0 Internazionale. 


\title{
Toufic El-Khoury, Beyrouth pantomime
}

\author{
Veronica Amadessi
}

\section{NOTIZIA}

TOUFIC EL KHOURY, Beyrouth pantomime, Paris, L'Harmattan, 2008, p. 152.

1 Primo romanzo del giovane scrittore libanese El-Khoury, Beyrouth pantomime narra con semplicità e precisione lo spaccato di una vita comune, pervasa dalla monotonia. Il protagonista, vinto dalla noia, vagabonda da un luogo all'altro della capitale, senza riuscire a lasciarsi sedurre dai sentimenti personali né dai grandi avvenimenti politici che hanno cambiato il Libano nell'ultimo ventennio. Incapace di abbandonarsi a qualsiasi entusiasmo, il giovane si lascia scorrere addosso la vita, che assume la forma di amanti, amici, manifestazioni politiche, incombenze universitarie, senza nessuna reazione. Personaggio anonimo, privo di spessore nelle azioni e nei dialoghi, il ragazzo rappresenta il paradosso di essere al centro di una storia che non varrebbe la pena di raccontare. La sensazione di inutilità e di nichilismo pervade a tal punto il romanzo che perfino i titoli dei capitoli, di un'estrema concisione, ritornano e vengono ripetuti, chiudendo il cerchio della narrazione. Lo stile fluido, senza troppi abbellimenti, ricorre spesso a dialoghi e situazioni che ricordano il teatro dell'assurdo, come a voler svuotare di significato una Storia troppo carica di conseguenze e di passioni. La sobrietà con cui l'autore riesce a trasmettere questo senso soffocante di monotonia ed indifferenza possiede una forza straordinaria, poiché dipinge con precisione l'attesa di un cambiamento che non avviene. Nelle sue interviste El-Khoury riesce paradossalmente a definire il suo romanzo per quel che non è: non è un testo politico, non è un testo autobiografico, non è un romanzo filosofico. L'idea di base del testo era solo di prendere un personaggio vuoto e di fargli attraversare 150 pagine senza pensare. Si capisce allora che tutto è affidato alle azioni dei personaggi cosiddetti minori, come in 
una rappresentazione muta (da cui il titolo), e che Beyrouth, sfondo di tutti gli episodi, assume il ruolo di vero protagonista. 